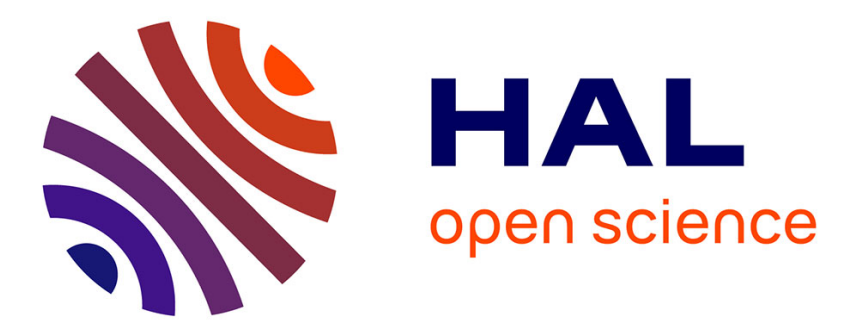

\title{
Surface core level spectroscopy of the Pt25Co75 (110) and (100) alloy surfaces
}

J. Thiele, C. Guillot, N. Barrett, R. Belkhou, P. Dolle, R. Baudoing-Savois

\section{To cite this version:}

J. Thiele, C. Guillot, N. Barrett, R. Belkhou, P. Dolle, et al.. Surface core level spectroscopy of the Pt25Co75 (110) and (100) alloy surfaces. Journal de Physique IV Proceedings, 1994, 04 (C9), pp.C9-135-C9-139. 10.1051/jp4:1994920 . jpa-00253481

\section{HAL Id: jpa-00253481 https://hal.science/jpa-00253481}

Submitted on 1 Jan 1994

HAL is a multi-disciplinary open access archive for the deposit and dissemination of scientific research documents, whether they are published or not. The documents may come from teaching and research institutions in France or abroad, or from public or private research centers.
L'archive ouverte pluridisciplinaire HAL, est destinée au dépôt et à la diffusion de documents scientifiques de niveau recherche, publiés ou non, émanant des établissements d'enseignement et de recherche français ou étrangers, des laboratoires publics ou privés. 


\title{
Surface core level spectroscopy of the $\operatorname{Pt}_{25} \operatorname{Co75}(110)$ and (100) alloy surfaces
}

\author{
J. Thiele*,**, C. Guillot*,**, N.T. Barrett*,**, R. Belkhou**, P. Dolle*** and R. Baudoing-Savois*** \\ * DRECAMISRSIM CE-Saclay, 91191 Gif-sur-Yvette cedex, France \\ ** LURE, Bâtiment 209D, Université Paris Sud, 91405 Orsay cedex, France \\ **** Laboratoire de Cristallographie, CNRS, BP. 166, 38042 Grenoble, France
}

\begin{abstract}
Core level photoemission spectroscopy of the $\mathrm{Pt} 4 \mathrm{f} 7 / 2$ level is used to investigate the surface and bulk Pt environments in the disordered alloy $\mathrm{Pt} 25 \mathrm{Co} 75$. For the (110) face no $\mathrm{Pt}$ is observed at the surface, and only a single Pt bulk site is identified with a chemical shift of $250 \mathrm{meV}$. For the denser (100) face the same bulk site is observed together with a surface peak, corresponding to a surface layer with Pt enrichment. The chemical shift at the surface is weaker than in the bulk.
\end{abstract}

\section{INTRODUCTION}

$\mathrm{Pt}-\mathrm{M}$ alloys (where $\mathrm{M}$ is a $3 \mathrm{~d}$ transition metal) have a great number of potential applications in the field of catalysis (e.g. $\mathrm{M}=\mathrm{Fe}$ : [1,2]; $\mathrm{M}=\mathrm{Co}$ : [3]) and as magnetic devices (e.g. $\mathrm{M}=\mathrm{Co}$ : [4]). The studies of single crystal surfaces have shown interesting segregation phenomena $[5,6]$. To understand and predict these effects with theoretical models, different surface structures have to be carefully investigated. The relevant energy terms for the understanding of a semi-infinite crystal surface will also be important for diffusion at interfaces of lower dimensional systems such as deposited thin films or multilayers.

Various surface analysis techniques allow the determination of the concentration of the surface plane, but quantitative Low Energy Electron Diffraction (LEED) studies have proved their worth in determining layer concentrations of the adjacent planes as well $[5,6]$.

It is well established that photoemission core level spectroscopy (PES) is sensitive to changes in the local environment of the emitter atom [7]. Limiting the elastic escape depth of the photoelectrons by the use of tunable synchrotron radiation makes it possible to distinguish between surface and bulk atoms, and to measure their respective core level shifts [8]. As well as the surface core level shift due to the structural difference between atoms at the surface and in the bulk, a shift caused by changes in the chemical environment can be measured. Thus, the core level shifts can be used as probe for changes in the chemical and structural environment of an emitter.

To test the facilities of PES for study surface segregation effets we have investigated two different surfaces (110) and (100) of a $\mathrm{Pt}_{25 \mathrm{Co}} 5$ single crystal in the disordered alloy phase and compared them to 


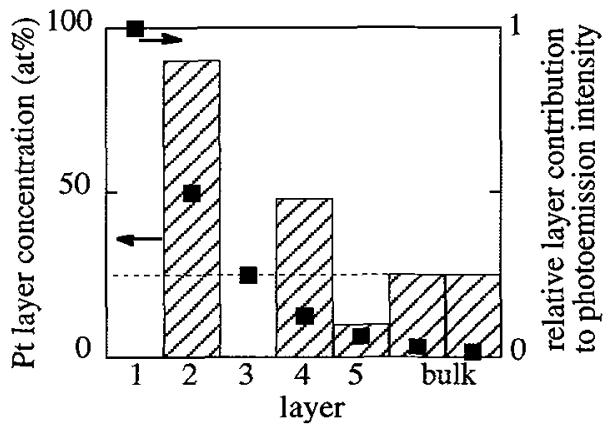

Figure 1: Oscillation of the Pt concentration (per layer) profile versus depth (layer $1=$ surface layer) of the $\mathrm{Pt}_{25} \mathrm{Co}_{75}$ (110) surface (from [6]). The squares show the relative contribution of each layer to the photoemission intensity of a pure $\mathrm{Pt}$ sample for a small photoelectron elastic mean free path $(5 \AA)$, typical of that obtained by synchrotron radiation. Photoelectron diffraction effects are neglected in the calculation of the layer by layer intensities.

LEED results. For the $(110)$ surface it was shown that the selvedge is a sequence of almost pure layers [6]: surface plane 100\% Co, second plane $90 \% \mathrm{Pt}$ and third plane $100 \%$ Co (fig. 1). The oscillation is weaker for the next two layers (50\% Pt and $11 \% \mathrm{Pt}$ ) before reaching the bulk composition of $25 \% \mathrm{Pt}$.

This behavior is quite well described by a theoretical model developed by Tréglia, Legrand and coworkers for the similar Pt-Ni system using a tight binding Ising model $[9,10]$. Contrary to the segregation of $\mathrm{M}$ for the open (110) surface, this model predicts for the dense surfaces of the fcc crystal an enrichment of Pt. This was indeed shown by quantitative LEED experiments on the Pt25C075 (111) surface (46\% Pt at the surface) [11]. Thus, one might expect a segregation of $\mathrm{Pt}$ for the (100) surface studied in this paper, where no such definitive LEED investigation exists, but preliminary results using Auger spectroscopy at various angles of incidence give good indication of this trend, even in presence of a $(5 \times 1)$ reconstructed surface [12].

In this paper we present core level photoemission results of the single crystal alloy $\mathrm{Pt}_{25} \mathrm{Co} 75$ for the (100) and (110) orientations. These results will be an important reference for the study of diffusion at Pt-Co interfaces. By estimating that the core level shift depends linearly on the chemical environment around the emitter we can obtain information on the degree of interdiffusion. To check this estimation we compare our results with the theoretical shift calculated using the approach proposed by Johansson and Martensson (et.al.) $[13,14]$.

\section{EXPERIMENT}

Both samples were spark cut from the same single crystal rod to produce $2 \mathrm{~mm}$ thick slabs $\left(8 \times 10 \mathrm{~mm}^{2}\right)$. The composition of the samples was checked by fluorescence measurements and Bragg Xray reflection. After mechanical polishing and checking of the orientation by Laue diffraction, clean surfaces were obtained in a UHV-chamber (base pressure $210^{-10}$ Torr) by repeated cycles of Argon ion bombardment $\left(400 \mathrm{eV}, 15 \mathrm{~mA} / \mathrm{cm}^{2}\right)$ and annealing at $750^{\circ} \mathrm{C}$. The cleanliness of the surfaces was checked by Auger electron spectroscopy. The (110) surface showed the same LEED spot intensity energy dependence already reported [6]. The LEED pattern of the (100) surface showed " $(1 \mathrm{xN})$ " structure (with $4 \leq N \leq 7$, where $N$ may be incommensurate, corresponding to satellites at $\pm q=a^{*} / N$ and $\pm 2 q$ ) depending on the annealing temperature and time [12]. In addition a weak $c(2 \times 2)$ structure was always present, especially for high electron energies. Experiments were carried out with the (1x5) superstructure.

The experiments were performed at the Super ACO storage ring, Orsay, France (beamline SA73b). A TGM $7^{\circ}$ monochromator was used, giving a overall resolution of 300-500 meV for photon 
energies between $110-190 \mathrm{eV}$. The core level 4f7/2 of Pt (binding energy in the pure Pt bulk $71.15 \mathrm{eV}$ [15]) was studied. To separate surface and bulk emission, we have changed the energy of the synchrotron radiation to privilege surface emission at smaller photon energies due to the smaller elastic mean free path of the photoelectrons [16]. Additionally, we have exposed the surfaces to $10 \mathrm{~L}$ of carbon monoxide.

\section{RESULTS AND DISCUSSION}

Adsorption of $\mathrm{CO}$ shifts the $4 \mathrm{f} 7 / 2$ core level of surface $\mathrm{Pt}$ by about $1 \mathrm{eV}$ to higher binding energy [15]. It is possible to determine the position of the photoemission peak emitted by the atoms at the surface from the difference spectrum of the surface before and after $\mathrm{CO}$ adsorption. This is shown in fig.2a) for the (100) surface. The spectra have been normalised to the continuous background and a linear background function was substracted. A part of the surface intensity (position $\approx 70.9 \mathrm{eV}$ ) is shifted due to the chemical influence of the $\mathrm{CO}(\approx 71.8 \mathrm{eV})$. The unchanged part of the spectrum (between 71.3 and71.6eV) has to come from the bulk. This gives us a rough estimate of the positons of the core levels coresponding to the surface and bulk atoms and shows that the influence of the $\mathrm{CO}$ on the Pt core level at the alloy surface is comparable to that on pure Pt surfaces. The same procedure of the (110) surface (fig.2b) shows only a slight reduction of the total intensity of the spectrum (due to attenuation of the photoemission signal by the CO layer), but no displacement was observed. We conclude, that there is no $P t$ in the surface plane.

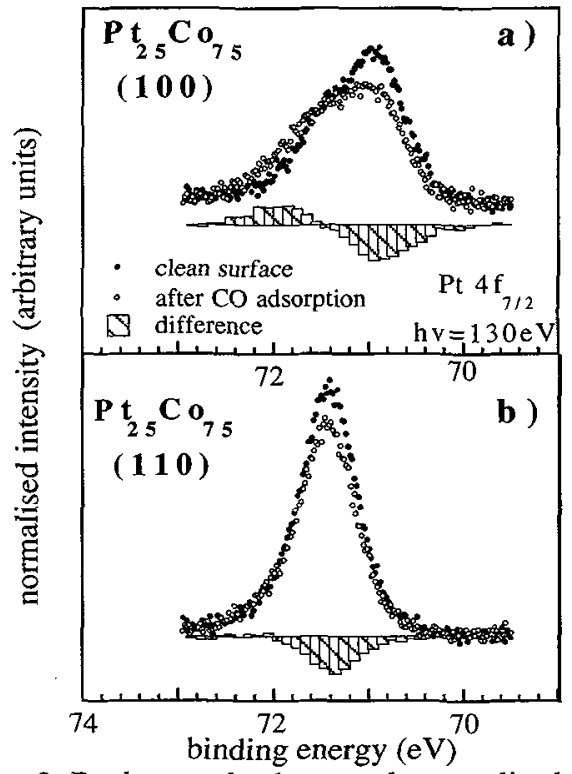

Figure 2: Background substracted, normalised data showing the Pt $4 \mathrm{f} 7 / 2$ spectra of the clean alloy surfaces and the $\mathrm{CO}$ adsorbed surfaces and the respective difference spectra:

a) $\mathrm{Pt}_{25 \mathrm{Co}} 75$ (100); b) Pt25C075 (110).

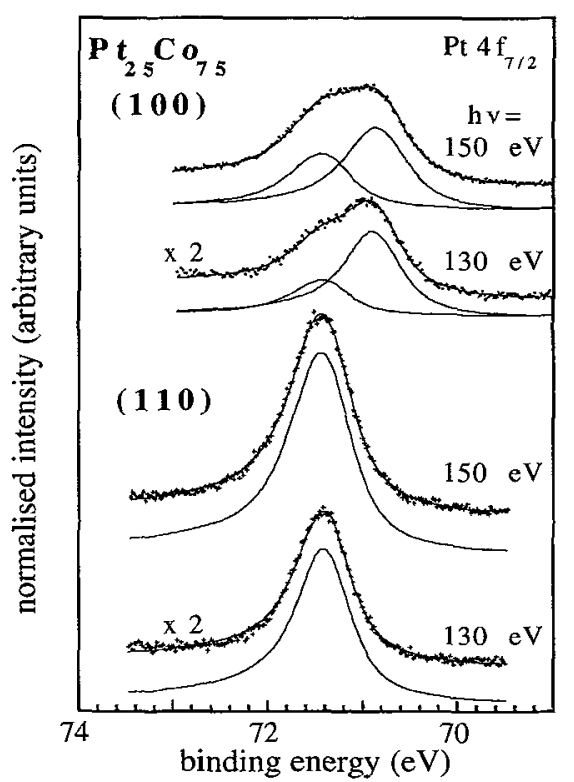

Figure 3: Decomposition of the Pt 4f7/2 spectra for two different photon energies of the (100) and the (110) surface. 
To fit the line shape of the Pt $4 \mathrm{f} 7 / 2$ core level, the "Rainbow" analysis program was used. A continuous "stepped" background (Shirley type [17]) was substracted. A Doniach-Sunjic line shape [18] was fitted, broadened by a Gaussian instrument function (width determined at the Fermi level corresponding to each photon energy). For the (110) surface it was possible to fit a single peak independently of the photon energy with a Lorentzian width $2 \Gamma=0.5 \mathrm{eV}$ and an asymmetry parameter $\alpha=0.11$, similar to those of pure Pt [15]. This supports the hypothesis of a single mean Pt bulk environment. Two examples of the decomposition for different photon energies ( $\mathrm{hv}=130 \mathrm{eV}$ and $150 \mathrm{eV}$ ) are given in fig. 3. Intensities are normalised with respect to the continuous background at a fixed point from the Fermi level, chosen so as to be on the low binding energy side of the $4 f 7 / 2$ line and thus unaffected by the asymmetric energy loss tail of the core emission. The mean position found for the corresponding core level binding energy is $71.39 \pm 0.04 \mathrm{eV}$. Despite the strong interplanar concentration oscillations as measured by LEED, this result shows that the mean local environment of Pt atoms near the surface is not radically different from that in the bulk. Hence we observe only a single photoemission peak despite the strong oscillatory depth profile.

For the (100) surface the fitting procedure with the same parameters as mentioned above leads to a binding energy of $71.41 \pm 0.04 \mathrm{eV}$ for the bulk peak and of $70.86 \pm 0.05 \mathrm{eV}$ for the surface peak. Fig. 3 shows clearly the relative decrease of surface emission with the increasing elastic mean free path of the photoelectrons, as well as the increase of the total intensity due to the increasing cross section of Pt 4f $7 / 2$ level. The relative intensity difference between the two surfaces can be explained by the exponential attenuation of the intensity contribution of each layer with increasing distance from the surface, see fig. 1. For the (110) selvedge the second layer shows a strongly enhanced Pt concentration and thus leads to the apparent increase of intensity.

The average binding energy for the Pt $4 \mathrm{f} 7 / 2$ core level in the bulk Pt25Co75 is thus $71.40 \pm 0.04 \mathrm{eV}$, corresponding to a chemical core level shift of $+250 \mathrm{meV}$ relative to the binding energy in pure $\mathrm{Pt}$. On the other hand, the surface peak is shifted by only $+60 \mathrm{meV}$ in respect to the clean $\mathrm{Pt}(100)$ surface line [19]. Thus, the alloy shift at the surface is smaller than in the bulk.

As it was already shown [15], it is possible to estimate the concentration in the surface plane from the comparison of the intensity of the surface peak with that of the corresponding clean $\mathrm{Pt}$ surface. Keeping the same photon energy and identical experiment parameters we can deduce a concentration of $42 \pm 5 \% \mathrm{Pt}$ at this surface. This value neglects photoelectron diffraction effects, which may differ between the Pt (100) surface and the $\mathrm{P}_{25} \mathrm{Co} 75$ (100) surface, but is consistent with the preliminary surface composition of about 50\%, obtained from the Auger spectroscopy measurements at variable angle of incidence [12].

The chemical core level shift for the bulk can be calculated by correlating the binding energy shift to the energy of solution in metals, based on a Born-Haber thermodynamical cycle, originally developed by Johansson and Martensson et al. [13,14]. For a very dilute alloy $\mathcal{A B}$ (concentration $(\mathrm{A})<10 \%$ ) the shift $\mathrm{E}_{\mathrm{A}}(\mathscr{A B})$ for $\mathrm{A}$ is expressed as follows:

$$
\mathrm{E}_{\mathrm{A}}(\mathscr{A} \mathcal{B})=\mathrm{E}(\mathrm{A}, \mathrm{B})+\mathrm{E}(\mathrm{A}+1, \mathrm{~A})-\mathrm{E}(\mathrm{A}+1, \mathrm{~B})
$$

$E(A, B)$ represents the partial solution energy of $A$ in $B, A+1$ denotes the element having a core charge $Z+1$ (in this case: $A \Leftrightarrow P t, B \Leftrightarrow C o$ and $A+1 \Leftrightarrow A u$ ). Using the semi-empirical formula for the solution 
energy proposed by Miedema et al. [20], we have calculated the following values:

$$
\mathrm{E}(\mathrm{Pt}, \mathrm{Co})=0.26 \mathrm{eV} / \mathrm{at}, \mathrm{E}(\mathrm{Au}, \mathrm{Pt})=-0.19 \mathrm{eV} / \mathrm{at} \text { and } \mathrm{E}(\mathrm{Au}, \mathrm{Co})=-0.35 \mathrm{eV} / \mathrm{at} \text {. }
$$

This leads to a shift of $+420 \mathrm{meV}$ for the case of $\mathrm{Pt}$ in a very Co rich environment. If we suppose a linear relation between the chemical shift and $\mathrm{Pt}$ concentration we find a theoretical chemical shift for $\mathrm{Pt}$ in $\mathrm{Pt}_{25} \mathrm{C} 075$ of about $300 \mathrm{meV}$, in good agreement with the experimental value of $250 \mathrm{meV}$.

\section{CONCLUSION}

We have studied two different faces of the disordered alloy $\mathrm{P} 25 \mathrm{Co} 75$ by core level spectroscopy. For the surface (110) we find a pure Co surface layer and confirm the results of quantitative LEED experiments. For the surface (100) we observe Pt segregation (42\% Pt) at the surface. The measured mean position of the Pt $4 \mathrm{f} 7 / 2$ core level is $71.40 \mathrm{eV}$ for the bulk, giving a chemical core level shift of $250 \mathrm{meV}$ relative to the pure $\mathrm{Pt}$ bulk, which is in good agreement with the calculated theoretical value. Comparison between the surface core level binding energy of the alloy (100) and a pure $\mathrm{Pt}(100)$ surface $(\Delta=60 \mathrm{meV}$ ) reveals variable chemical shift due to the Co on the Pt core level in the bulk and at the surface.

\section{References}

[1] Beccat P., Bertolini J.C., Gauthier Y., Massardier J. and Ruiz P., J.Catal. 126 (1990) 451.

[2] Bertolini J.C. and Massardier J., Catal. Lett. 9 (1991) 183.

[3] Ross P.N., J, Vac. Technol. A 10 (1992) 2546.

[4] Weller D., Brändle H., Gorman G., Lin C.-J. and Notarys H., Appl. Phys. Lett. 61 (1992) 2726.

[5] Gauthier Y., Joly Y., Baudoing R. and Rundgren J ., Phys. Rev. B 31 (1985) 6216.

[6] Bugnard J. M., Baudoing-Savois R., Gauthier Y. and Hill E.K., Surf. Sci. 281 (1993) 62.

[7] Cardona M. and Ley L., Topics in Applied Physics -Photoemission in Solids I- Vol.26 (SpringerVerlag, Berlin Heidelberg New York,1978) pp. 60-79

[8] Spanjaard D., Guillot C., Desjonquères M.C., Tréglia G. and Lecante J., Surf. Sci. Rep. 5 (1985)1.

[9] Tréglia G. and Legrand B., Phys. Rev. B 35 (1987) 4338.

[10] Legrand B., Tréglia G. and Ducastelle F., Phys. Rev. B 41 (1990) 4422.

[11] Gauthier Y., Baudoing-Savois R., Rosnik J.J.W.M. and Sotto M., Surf. Sci. 297 (1993) 193.

[12] Baudoing-Savois R., Bugnard J.M., Rosnik J.J.W.M., Gauthier Y., Dolle P. and Sotto M., ECOSS 13, Warwick 31 August-4 September 1993.

[13] Johansson B. and Martensson N., Phys. Rev. B 21 (1980) 4427.

[14] Steiner P., Hüfner S., Martensson N. and Johansson B., Solid. State. Comm. 37 (1980) 73.

[15] Belkhou R., Barrett N.T., Guillot C., Fang M., Barbier A., Eugène J., Carrière B., Naumovic D. and Osterwalder J., Surf. Sci. 297 (1993) 40; and references there in.

[16] Brundle C.R., Surf. Sci. 45 (1975) 99.

[17] Shirley D.A., Phys. Rev. B 5 (1972) 4709.

[18] Doniach S. and Sunjic M., J. Phys. C 3 (1970) 285.

[19] Boeglin C., Carrière B., Deville J.P. and Scheurer F., Phys. Rev. B 45 (1992) 3834.

[20] Miedema A.R., Boom R. and de Boer F.R., J. Less Common Met. 41 (1975) 283. 